\title{
Diferentes tipos de milheto utilizados na alimentação de suínos em crescimento e terminação
}

\author{
Different types of pearl millets (Pennisetum glaucum (L.) R. Brown) on growing -finishing \\ pigs feeding
}

\author{
Ivan Moreira $^{\mathrm{I}^{*}}$ Alexandre Orio Bastos ${ }^{\mathrm{II}}$ Cláudio Scapinelo ${ }^{\mathrm{I}}$ Alessandro Luís Fraga ${ }^{\mathrm{III}}$ \\ Marianne Kutschenko ${ }^{\mathrm{IV}}$
}

\section{RESUMO}

Um experimento de desempenho foi conduzido com o objetivo de avaliar a viabilidade nutricional e econômica da utilização de rações com diferentes tipos de milheto, com nível de inclusão de $60 \%$, na alimentação de suínos, nas fases de crescimento e terminação. Foram utilizados 40 suínos híbridos na fase de crescimento $(30,3 \pm 2,9 \mathrm{~kg})$ e terminação $(54,3 \pm 4,1 \mathrm{~kg})$, distribuídos em um delineamento em blocos casualizados, com cinco tratamentos, quatro blocos e dois suínos por unidade experimental. Os tratamentos consistiram de uma ração à base de milho e farelo de soja e outras quatro com a inclusão de $60 \%$ de diferentes tipos de milheto (IAPAR, COMUM, BN2 e BN2S, sendo este com espigueta). Não foram observadas diferenças entre os tipos de milheto para consumo diário de ração, ganho diário de peso, conversão alimentar e características de carcaça. Os resultados sugerem que é viável a inclusão de $60 \%$ de milheto da linhagem IAPAR, da cultivar "COMUM", das variedades BN2 ou BN2S (com a espigueta), nas rações de suínos em crescimento e terminação.

Palavras-chave: alimento alternativo, análise econômica, características de carcaça, desempenho.

\section{ABSTRACT}

A performance trial was carried out to evaluate the nutritional and economic feasibility of growing-finishing pig diets with $60 \%$ of different pearl millets. Forty crossbreed pigs were used during growing (initial weight $30.3 \pm 2.9 \mathrm{~kg}$ ) and finishing $(54.3 \pm 4.1 \mathrm{~kg})$ phases. Pigs were allotted in a randomized blocks design with 5 treatments, 4 blocs and 2 pigs per experimental unit. The treatments consisted in a cornsoybean meal and other 4 diets containing $60 \%$ of inclusion of different types of pearl millet (IAPAR, COMUM, BN2 and BN2S. The last is pearl millet BN2 in spikelets). There was not difference for types of pearl millet on daily feed intake, daily weight gain, feed: gain ratio and carcass traits. The results suggested that it is possible to use $60 \%$ of IAPAR, COMUM, BN2 and BN2S pearl millet in growing-finishing pig diets.

Key words: alternative feedstuffs, carcass traits, economic analysis, performance.

\section{INTRODUÇÃO}

No Brasil, o milho e o farelo de soja são os principais componentes das rações para suínos, o que torna o custo das rações fortemente dependentes das variações dos preços desses ingredientes. Por serem "commodities", os preços desses alimentos no Brasil são influenciados pelos preços internacionais, o que ocasiona instabilidade para os seus setores consumidores. Assim, a procura por alimentos alternativos é sempre uma preocupação dos componentes da cadeia produtiva da carne suína.

O milheto grão vem sendo testado como fonte alternativa de alimento para suínos (ADEOLA \& ORBAN, 1995; BANDEIRA et al., 1996; BASTOS et al., 2002; BASTOS et al., 2005) e aves (RODRIGUES et al, 2001). Isso tem ocorrido em função do bom desenvolvimento do milheto em condições adversas de clima e solo brasileiros, o que levou ao aumento de áreas ocupadas com esta cultura. $\mathrm{O}$ cultivo do milheto se destaca pela boa produção em solos de baixa fertilidade, altos índices de alumínio ou, ainda, em

IDepartamento de Zootecnia, Universidade Estadual de Maringá (UEM). Av. Colombo, 5790, 87020-900, Maringá, PR, Brasil. Email: imoreira@uem.br. *Autor para correspondência.

IIMAPA-DFA/Paraná, Curitiba, PR, Brasil.

III Universidade Federal do Mato Grosso (UFMT), Rondonópolis, MT, Brasil.

${ }^{\mathrm{IV}}$ Ajinomoto Biolatina, São Paulo, São Paulo, Brasil. 
regiões com baixos índices de pluviosidade (ANDREWS \& KUMAR, 1992).

Novas variedades e cultivares de milheto têm sido desenvolvidas e disponibilizadas no mercado brasileiro (BONAMIGO, 1999; GERALDO, 2000). Apesar de os cultivares de milheto no Brasil voltaremse principalmente para a produção de palhada, a introdução de genótipos selecionados para a produção de grãos poderia produzir renda adicional aos produtores (GERALDO et al., 2000).

A composição média do milheto apresenta teor de proteína bruta ao redor de $12 \%$, de carboidratos, $69 \%$, de lipídeos, $5 \%$, de fibra bruta, $5 \%$ e de matéria mineral ao redor de 2,5\% (HULSE et al., 1980). Não raro, o nível de proteína supera $15 \%$, o que, para a alimentação de suínos, poderia representar diminuição no uso de farelo de soja e conseqüente redução de custo da ração. Além disto, tem-se verificado que o milheto possui maior quantidade de aminoácidos essenciais (lisina, metionina e treonina) que o milho (ADEOLA \& ORBAN, 1995).

A substituição do milho pelo milheto como fonte energética na alimentação de suínos pode ser feita sem limites, desde que seja corrigido o nível energético da ração, devido ao menor teor de energia digestível do milheto (NICOLAIEWSKY \& PRATES, 1987). Trabalhando com rações isonutritivas, com níveis de $0,25,50,75$ e $100 \%$ de substituição do milho pelo milheto em suínos na fase de crescimento, NUNES et al. (1997) não encontraram diferença no desempenho. Da mesma forma, BANDEIRA et al. (1996), utilizando os mesmos níveis de substituição na fase de terminação, não encontraram diferenças nas características de carcaça quando os suínos foram alimentados com níveis de substituição de até $100 \%$.

A maioria das pesquisas com milheto não identifica a cultivar utilizada. Entretanto, BASTOS et al. (2005) verificaram que as diferentes cultivares de milheto apresentam variações em sua composição química, que podem resultar em diferenças no valor nutricional entre elas. Assim, é importante que se identifique as cultivares e se estude o efeito da sua utilização em rações práticas de suínos, em função da disponibilização de novas cultivares no mercado brasileiro.

Neste contexto, o objetivo deste trabalho foi o de estudar o efeito da utilização de diferentes tipos de milheto presentes no mercado brasileiro sobre desempenho, características de carcaça e viabilidade econômica de suínos nas fases de crescimento e terminação.

\section{MATERIAL E MÉTODOS}

Foram utilizados 40 suínos híbridos (Landrace, Large White e Duroc), com peso inicial de $30,30 \pm 2,87 \mathrm{~kg}$, para a fase de crescimento e $54,30 \pm 4,07 \mathrm{~kg}$ para a fase de terminação. Para a fase de terminação, os animais foram redistribuídos entre os tratamentos, com o objetivo de isolar o possível efeito residual do crescimento sobre a terminação. Os animais foram alojados em baias com $7,60 \mathrm{~m}^{2}$, que possuíam um comedouro semi-automático e um bebedouro do tipo chupeta.

Os tipos de milheto utilizados foram IAPARIA98301, COMUM, BN2, e BN2S, este último com espigueta, cujas composições químicas e energéticas são apresentadas na tabela 1 . Os milhetos foram moídos em peneira de $2 \mathrm{~mm}$, objetivando melhorar seu valor nutricional (BASTOS et al., 2005).

Foram utilizados dois tipos de ração: crescimento $(30-55 \mathrm{~kg})$ e terminação $(55-90 \mathrm{~kg})$. As rações (Tabelas 2 e 3 ) foram formuladas para atender às exigências do NRC (1998). Os cinco tratamentos consistiram de uma ração controle, à base de milho e farelo de soja, e quatro rações que continham cada uma, $60 \%$ de um dos tipos de milheto estudados. Para a formulação das rações, foram utilizados os valores de composição química e energética dos alimentos, constantes da tabela 1, indicados por BASTOS et al. (2005).

Ao final do período experimental (28 dias no crescimento e 42 dias na terminação), após período de $24 \mathrm{~h}$ de jejum, foram abatidos 15 animais, três por tratamento (dois machos castrados e uma fêmea), determinando-se as características de carcaça de acordo com o "Método Brasileiro de Classificação de Carcaças" (ABCS, 1973). Os rendimentos de carcaça e de pernil foram calculados em relação à carcaça resfriada em câmara fria por $24 \mathrm{~h} \mathrm{a} 3^{\circ} \mathrm{C}$. Os animais abatidos foram escolhidos por apresentarem pesos próximos à média do tratamento a que pertencia.

Foi realizada avaliação do estômago dos animais abatidos para verificar a presença de úlceras, de acordo com metodologia descrita por NIELSEN \& INGVARTSEN(2000).

Foi feita a análise da eficiência econômica da utilização do milheto em cada um dos tratamentos, seguindo metodologia indicada por BELLAVER et al. (1985) e GOMES et al. (1991). Para isso, foi estimado o custo em ração por quilograma de suíno vivo produzido, e então calculado o Índice de Eficiência Econômica (IEE) e o Índice do Custo Médio (ICM). 
Tabela 1 - Composição química e energética dos diferentes tipos de milheto utilizados nas rações experimentais (valores na matéria natural) ${ }^{1}$.

\begin{tabular}{|c|c|c|c|c|}
\hline \multirow{2}{*}{ Nutrientes } & \multicolumn{4}{|c|}{ Tipos de milheto } \\
\hline & IAPAR & COMUM & $\mathrm{BN} 2$ & BN2S \\
\hline Matéria seca, $\%$ & 88,93 & 90,46 & 87,31 & 88,93 \\
\hline Proteína bruta, $\%$ & 11,14 & 14,07 & 14,07 & 15,58 \\
\hline Lisina, $\%$ & 0,32 & 0,33 & 0,34 & ND \\
\hline Metionina + cistina, $\%$ & 0,40 & 0,51 & 0,52 & ND \\
\hline Treonina, $\%$ & 0,46 & 0,53 & 0,47 & ND \\
\hline Energia digestível, $\mathrm{kcal} / \mathrm{kg}$ & 3.181 & 3.022 & 3.107 & $3.107^{2}$ \\
\hline Fibra bruta, $\%$ & 1,25 & 1,05 & 1,15 & 2,96 \\
\hline Cálcio, \% & 0,05 & 0,05 & 0,05 & 0,07 \\
\hline Fósforo total, \% & 0,29 & 0,25 & 0,31 & 0,30 \\
\hline
\end{tabular}

${ }^{1}$ Valores analisados em laboratório (BASTOS et al., 2005). ${ }^{2}$ Estimada, considerando o mesmo valor do BN2. ND = Não disponível.

Para tanto, foi considerado o preço dos ingredientes no mercado local, à época do término do experimento.

O delineamento experimental foi o de blocos ao acaso, com cinco tratamentos e quatro blocos (formados em função do peso dos animais), sendo cada unidade experimental formada por dois animais (um macho castrado e uma fêmea). Na avaliação de carcaça, cada unidade experimental foi formada por um animal abatido, com três repetições/tratamento.

As variáveis de desempenho, de características de carcaça e de viabilidade econômica foram submetidas à análise de variância, utilizando-se o pacote estatístico SAEG (UFV, 1997). Foi utilizado o

Tabela 2 - Composição percentual, química e energética e DGM das rações experimentais para os suínos na fase de crescimento (30 - 55kg de peso vivo).

\begin{tabular}{|c|c|c|c|c|c|}
\hline \multirow{2}{*}{ Item } & \multirow{2}{*}{ Controle } & \multicolumn{4}{|c|}{ Tipos de milheto } \\
\hline & & IAPAR & COMUM & $\mathrm{BN} 2$ & $\mathrm{BN} 2 \mathrm{~S}$ \\
\hline \multicolumn{6}{|l|}{ Ingrediente, $\%{ }^{1}$} \\
\hline Milho & 72,26 & 16,35 & 20,48 & 21,73 & 23,41 \\
\hline Milheto & - & 60,00 & 60,00 & 60,00 & 60,00 \\
\hline Farelo de soja & 25,41 & 17,68 & 11,45 & 11,25 & 9,53 \\
\hline Óleo de soja & 0,00 & 3,38 & 5,22 & 4,21 & 4,19 \\
\hline Supl. vitamínico e mineral ${ }^{2}$ & 0,50 & 0,50 & 0,50 & 0,50 & 0,50 \\
\hline Sal & 0,40 & 0,40 & 0,40 & 0,40 & 0,40 \\
\hline L-lisina $\mathrm{HCl}$ & 0,016 & 0,24 & 0,42 & 0,39 & 0,41 \\
\hline Calcário calcítico & 0,61 & 0,62 & 0,62 & 0,62 & 0,61 \\
\hline Fosfato bicálcico & 0,90 & 0,93 & 1,01 & 1,02 & 1,03 \\
\hline \multicolumn{6}{|l|}{ Nutriente (valores calculados) } \\
\hline Energia digestível, kcal/kg & 3.380 & 3.380 & 3.380 & 3.380 & 3.380 \\
\hline Cálcio, \% & 0,56 & 0,56 & 0,56 & 0,56 & 0,56 \\
\hline Fósforo total, \% & 0,49 & 0,49 & 0,49 & 0,49 & 0,49 \\
\hline Lisina total, $\%$ & 0,90 & 0,90 & 0,90 & 0,90 & 0,90 \\
\hline Metionina+cistina total, $\%$ & 0,59 & 0,51 & 0,53 & 0,57 & 0,59 \\
\hline Treonina total, $\%$ & 0,69 & 0,62 & 0,59 & 0,59 & 0,60 \\
\hline DGM & 633 & 661 & 532 & 491 & 557 \\
\hline
\end{tabular}

${ }^{1}$ Valores expressos na matéria natural. ${ }^{2}$ Suplemento vitamínico e mineral - níveis nutricionais por kg de ração: Vit. A - 6.000 UI; Vit. D3 -

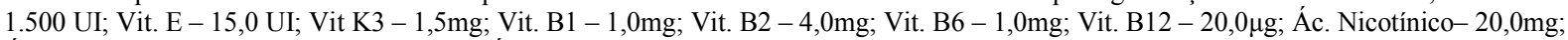
Ác. Pantotênico - 8,0mg; Biotina- 0,08mg; Ác. Fólico- 0,6mg; Selênio- 0,3mg; Colina- 120,0mg; Promotor de crescimento - 50,0mg; Antioxidante-100mg; Iodo- 1,5mg; Cobalto - 1,0mg; Cobre- 175,0mg; Zinco- 100,0mg; Ferro- 100,0mg; Manganês-40,0mg.

Ciência Rural, v.37, n.2, mar-abr, 2007. 
Tabela 3 - Composição percentual, química e energética das rações experimentais para os suínos na fase de terminação (55- 90 kg de peso vivo).

\begin{tabular}{|c|c|c|c|c|c|}
\hline \multirow{2}{*}{ Item } & \multirow{2}{*}{ Controle } & \multicolumn{4}{|c|}{ Tipos de milheto } \\
\hline & & IAPAR & COMUM & $\mathrm{BN} 2$ & $\mathrm{BN} 2 \mathrm{~S}$ \\
\hline \multicolumn{6}{|l|}{ Ingrediente, $\%{ }^{1}$} \\
\hline Milho & 83,79 & 24,52 & 26,16 & 27,33 & 30,05 \\
\hline Milheto & - & 60,00 & 60,00 & 60,00 & 60,00 \\
\hline Farelo de soja & 13,80 & 9,858 & 6,20 & 6,09 & 3,29 \\
\hline Óleo de soja & - & 314 & 5,01 & 3,99 & 3,97 \\
\hline Supl. vitamínico e mineral ${ }^{2}$ & 0,50 & 0,50 & 0,50 & 0,50 & 0,50 \\
\hline Sal & 0,40 & 0,40 & 0,40 & 0,40 & 0,40 \\
\hline L-lisina $\mathrm{HCl}$ & 0,225 & 0,33 & 0,42 & 0,39 & 0,45 \\
\hline Calcário calcítico & 0,58 & 0,61 & 0,62 & 0,62 & 0,62 \\
\hline Fosfato bicálcico & 0,80 & 0,75 & 0,78 & 0,77 & 0,82 \\
\hline \multicolumn{6}{|l|}{ Nutriente (valores calculados) } \\
\hline Energia digestível, $\mathrm{kcal} / \mathrm{kg}$ & 3.396 & 3.380 & 3.380 & 3.380 & 3.380 \\
\hline Cálcio, \% & 0,49 & 0,49 & 0,49 & 0,49 & 0,49 \\
\hline Fósforo total, $\%$ & 0,43 & 0,43 & 0,43 & 0,43 & 0,43 \\
\hline Lisina total, $\%$ & 0,77 & 0,77 & 0,77 & 0,77 & 0,77 \\
\hline Metionina+cistina total, $\%$ & 0,49 & 0,44 & 0,47 & 0,53 & 0,54 \\
\hline Treonina total, $\%$ & 0,52 & 0,51 & 0,52 & 0,52 & 0,51 \\
\hline
\end{tabular}

${ }^{1}$ Valores expressos na matéria natural. ${ }^{2}$ Suplemento vitamínico e mineral - níveis nutricionais por kg de ração: Vit. A - 3.600 UI; Vit. D3 -

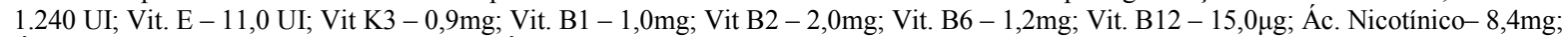
Ác. Pantotênico - 7,0mg; Biotina- 0,05mg; Ác. Fólico- 0,4mg; Selênio- 0,3mg; Colina- 120,0mg; Promotor de crescimento - 35,0mg; Antioxidante- 100mg; Iodo- 1,5mg; Cobalto - 1,0mg; Cobre- 175,0mg; Zinco- 70,0mg; Ferro- 70,0mg; Manganês- 28,0mg.

seguinte modelo matemático: $\mathrm{Y}_{i j}=\mu+\mathrm{B}_{i}+\mathrm{T}_{j}+\mathrm{e}_{i j}$, em que: $\mathrm{Y}_{i j}=$ valor observado da variável estudada, relativo a cada unidade experimental, recebendo o tipo de milheto $j$ do bloco $i ; \mu=$ constante geral; $\mathrm{B}_{i}=$ efeito do $i^{\text {śsimo }}$ bloco $\left(i=1,2,3\right.$ e 4); e $\mathrm{T}_{j}=$ efeito do tratamento $(j=1$, $2,3,4,5) ; \mathrm{e}_{i j}=$ erro aleatório associado a cada observação. Para testar a diferença entre as médias, foi utilizado o teste Student-Newman-Keuls $(\mathrm{P} \leq 0,05)$.

\section{RESULTADOS E DISCUSSÃO}

Os resultados de desempenho dos animais nas respectivas fases experimentais são apresentados na tabela 4. O consumo diário de ração, o ganho diário de peso e a conversão alimentar não diferiram $(\mathrm{P}>0,05)$ entre os tratamentos nas duas fases (crescimento e terminação), indicando que todos os tipos de milheto testados podem ser utilizados em rações para suínos. Os resultados são semelhantes aos obtidos por NUNES et al. (1997) e BASTOS et al. (2002), que também consideram viável, do ponto de vista nutricional, a utilização do milheto na alimentação de suínos.

O conhecimento da composição química e energética dos diferentes tipos de milheto (Tabela 1) permitiu formular rações (Tabelas 2 e 3 ) que possibilitaram desempenho similar entre eles, bem como à ração à base de milho e farelo de soja (Tabela 4).

$\mathrm{O}$ diâmetro dos furos das peneiras dos moinhos, pode influenciar os valores de digestibilidade dos nutrientes dos milhetos (BASTOS et al., 2005). A utilização de milhetos com moagem mais fina poderia provocar o aumento na incidência de ocorrência de lesões gástricas, pois a diminuição do tamanho da partícula torna o bolo alimentar mais aquoso e, portanto, com menor consistência, fatores que estão diretamente ligados com o aumento na ocorrência desse tipo de lesão (NIELSEN \& INGVARASTEN, 2000; KNUDSEN, 1997; JOHANSEN et al., 1996). As avaliações de estômago não mostraram lesões gástricas nos animais que receberam rações com os milhetos, fato que poderia ocorrer devido à granulometria mais fina das rações que continham os milhetos, comparada à ração sem milheto. Os valores de diâmetro geométrico médio (DGM) das rações (Tabela 2) estão dentro da faixa de 500 a $650 \mu \mathrm{m}$, que é o recomendado por ZANOTTO et al. (1999).

Não se observou diferença $(\mathrm{P}>0,05)$ entre as características de carcaça (Tabela 5) devido à utilização de diferentes tipos de milheto. Esses resultados são semelhantes aos obtidos por BASTOS et al. (2002), que testaram a inclusão de até $60 \%$ de 
Tabela 4 - Desempenho de suínos nas fases de crescimento e terminação, alimentados com rações contendo diferentes tipos de milheto.

\begin{tabular}{|c|c|c|c|c|c|c|c|c|}
\hline \multirow{2}{*}{ Item } & \multicolumn{6}{|c|}{ Tipos de milheto } & \multicolumn{2}{|c|}{ Análise de variância } \\
\hline & Controle & IAPAR & COMUM & $\mathrm{BN} 2$ & $\mathrm{BN} 2 \mathrm{~S}$ & Média & $\mathrm{CV}^{1} \%$ & Efeito $^{2}$ \\
\hline \multicolumn{9}{|c|}{ Fase de crescimento ( $30-55 \mathrm{~kg}$ de peso vivo) } \\
\hline Peso inicial, $\mathrm{kg}$ & 30,20 & 30,19 & 30,35 & 30,33 & 30,27 & 30,27 & - & - \\
\hline Consumo diário de ração, $\mathrm{kg}$ & 2,27 & 2,36 & 2,22 & 2,18 & 2,23 & 2,25 & 9,53 & $\mathrm{NS}^{3}$ \\
\hline Ganho diário de peso, $\mathrm{kg}$ & 0,846 & 0,884 & 0,898 & 0,815 & 0,831 & 0,854 & 7,54 & NS \\
\hline Conversão alimentar & 2,69 & 2,67 & 2,47 & 2,68 & 2,68 & 2,64 & 5,75 & NS \\
\hline Peso final, $\mathrm{kg}$ & 53,89 & 54,95 & 55,49 & 53,14 & 54,22 & 54,34 & - & - \\
\hline \multicolumn{9}{|c|}{ Fase de terminação (55-90 kg de peso vivo) } \\
\hline Peso inicial, $\mathrm{kg}$ & 54,59 & 53,94 & 54,16 & 54,52 & 54,02 & 54,25 & - & - \\
\hline Consumo diário de ração, $\mathrm{kg}$ & 2,39 & 2,54 & 2,38 & 2,44 & 2,30 & 2,41 & 9,91 & NS \\
\hline Ganho diário de peso, $\mathrm{kg}$ & 0,768 & 0,845 & 0,857 & 0,819 & 0,801 & 0,818 & 9,92 & NS \\
\hline Conversão alimentar & 3,13 & 3,05 & 2,84 & 3,02 & 2,91 & 2,99 & 6,30 & NS \\
\hline Peso final, $\mathrm{kg}$ & 86,83 & 89,41 & 90,16 & 88,94 & 87,46 & 88,56 & - & - \\
\hline
\end{tabular}

${ }^{1} \mathrm{CV}=$ Coeficiente de variação. ${ }^{2}$ Médias nas linhas, seguidas de letras diferentes, diferem $(\mathrm{P}>0,05)$ pelo teste Student Newman Keuls. ${ }^{3}$ NS $=$ Não significativo $(\mathrm{P}>0,05)$.

milheto e não observam diferenças nas características da carcaça dos suínos. BANDEIRA et al. (1996), trabalhando com níveis de substituição de até $100 \%$ do milho pelo milheto, também não encontraram diferenças nas características de carcaça. Como as rações foram balanceadas para serem isonutritivas, em função dos valores de digestibilidade determinados anteriormente por BASTOS et al. (2005), estes resultados confirmaram o esperado, ou seja, ausência de influência sobre as carcaças.

Os resultados do custo em ração do quilograma de suíno produzido, o índice de eficiência econômica e o índice de custo médio dos dois períodos (crescimento e terminação) são apresentados na tabela
6. A utilização do milheto COMUM para a fase de crescimento propiciou um menor custo em ração do quilograma de suíno produzido $(\mathrm{P}<0,05)$, quando comparado à ração à base de milho e farelo de soja, sendo semelhante $(\mathrm{P}>0,05)$, entretanto, aos outros milhetos. $\mathrm{O}$ índice de custo médio da ração controle foi $14,12 \%$ maior que a ração que continha $60 \%$ de milheto da cultivar COMUM.

Nas condições de mercado vigentes e na relação de preços, em que o milheto alcança $70 \%$ do custo do milho, a utilização do milheto em rações de suínos, independentemente do seu tipo, é viável economicamente. É importante ressaltar que foi considerada uma mesma relação de preço para o grão de milheto, e que a utilização do milheto com a espigueta

Tabela 5 - Características de carcaça de suínos, alimentados com rações contendo diferentes tipos de milheto.

\begin{tabular}{|c|c|c|c|c|c|c|c|c|}
\hline \multirow{2}{*}{ Item } & \multirow{2}{*}{ Controle } & \multicolumn{4}{|c|}{ Tipos de milheto } & \multirow{2}{*}{ Média } & \multicolumn{2}{|c|}{ Análise de variância } \\
\hline & & IAPAR & COMUM & $\mathrm{BN} 2$ & $\mathrm{BN} 2 \mathrm{~S}$ & & $\mathrm{CV}^{10} \%$ & Efeito $^{2}$ \\
\hline Peso médio ao abate, $\mathrm{kg}$ & 85,53 & 87,37 & 86,93 & 87,17 & 86,17 & 86,23 & - & - \\
\hline Rendimento de carcaça, \% & 82,77 & 81,63 & 82,89 & 81,88 & 81,64 & 82,16 & 3,64 & $\mathrm{NS}^{3}$ \\
\hline Espessura de toucinho, $\mathrm{cm}$ & 2,68 & 2,67 & 2,50 & 2,68 & 2,70 & 2,68 & 13,27 & NS \\
\hline Área de olho de lombo, $\mathrm{cm}^{2}$ & 36,78 & 37,6 & 39,25 & 43,37 & 39,28 & 39,26 & 7,99 & NS \\
\hline Relação gordura/carne & 0,46 & 0,48 & 0,54 & 0,44 & 0,43 & 0,47 & 17,63 & NS \\
\hline Rendimento de pernil, $\%$ & 31,40 & 30,85 & 31,30 & 32,06 & 31,31 & 31,39 & 4,44 & NS \\
\hline
\end{tabular}

${ }^{1}$ Coeficiente de variação. ${ }^{2}$ Médias nas linhas, seguidas de letras diferentes, diferem $(\mathrm{P}>0,05)$ pelo teste Student Newman Keuls. ${ }^{3}$ NS $=$ Não significativo $(\mathrm{P}>0,05)$. 
Tabela 6 - Custo do quilograma de ração, custo em ração do quilograma de suíno produzido (CR), índice de eficiência econômica (IEE) e índice de custo médio (IC), para suínos alimentados com diferentes tipos de milheto.

\begin{tabular}{|c|c|c|c|c|c|c|c|}
\hline \multirow{3}{*}{ Item } & \multirow{2}{*}{ Controle } & \multicolumn{4}{|c|}{ Tipos de milheto } & \multirow{3}{*}{$\mathrm{CV}^{10} \%$} & \multirow{3}{*}{ Efeito $^{3}$} \\
\hline & & IAPAR & COMUM & $\mathrm{BN} 2$ & $\mathrm{BN} 2 \mathrm{~S}$ & & \\
\hline & \multicolumn{5}{|c|}{ Fase de crescimento } & & \\
\hline Custo da ração ${ }^{2}, \mathrm{R} \$ / \mathrm{kg}$ & 0,255 & 0,240 & 0,243 & 0,233 & 0,229 & - & - \\
\hline CR, R\$/kg PV ganho & $0,686^{\mathrm{a}}$ & $0,640^{\mathrm{ab}}$ & $0,602^{\mathrm{b}}$ & $0,624^{\mathrm{ab}}$ & $0,613^{\mathrm{ab}}$ & 5,75 & 0,05 \\
\hline IEE & 88,13 & 94,83 & 100 & 96,69 & 98,33 & - & - \\
\hline IC & 114,12 & 106,22 & 100 & 103,61 & 101,74 & - & - \\
\hline \multicolumn{8}{|c|}{ Fase de terminação } \\
\hline Custo da ração, $\mathrm{R} \$ / \mathrm{kg}$ & 0,228 & 0,214 & 0,224 & 0,216 & 0,208 & - & - \\
\hline $\mathrm{CR}, \mathrm{R} \$ / \mathrm{kg}$ PV ganho & 0,708 & 0,639 & 0,629 & 0,653 & 0,578 & 6,44 & NS \\
\hline IEE & 84,74 & 94,21 & 96,67 & 91,73 & 100 & - & - \\
\hline IC & 118,60 & 106,99 & 105,19 & 109,21 & 100 & - & - \\
\hline
\end{tabular}

${ }^{, 1} \mathrm{CV}=$ Coeficiente de variação. ${ }^{2}$ Custos baseados em uma relação de preços para o milheto de $70 \%$ do valor (R\$) do milho. ${ }^{3}$ Médias nas linhas, seguidas de letras iguais, não diferem $(\mathrm{P}>0,05)$ pelo teste Student Newman Keuls.

pode representar um custo menor que o mesmo grão beneficiado e com qualidade de semente. Portanto, a inclusão de $60 \%$ de milheto em rações de suínos em crescimento, do ponto de vista econômico, é viável, independentemente do tipo de milheto utilizado.

\section{CONCLUSÃO}

E viável a inclusão de $60 \%$ de milheto da linhagem IAPAR, da cultivar "COMUM", das variedades BN2 ou BN2S (com a espigueta), na alimentação de suínos em crescimento e terminação.

\section{AGRADECIMENTOS}

À FUNDAÇÃO ARAUCÁRIA e ao INSTITUTO AGRONÔMICO DO PARANÁ (IAPAR), pela colaboração na condução da pesquisa.

\section{REFERÊNCIAS}

ADEOLA, O.; ORBAN, J.I. Chemical composition and nutrient digestibility of pearl millet (Pennisetum glaucum) fed to growing pigs. Journal of Cereal Science, v.22, p.177-184, 1995.

ANDREWS, D.J.; KUMAR, K.A. Pearl millet for food, feed, and forage. Advances in Agronomy, v.48, p.89-139, 1992.

ASSOCIAÇÃO BRASILEIRA DE CRIADORES DE SUÍNOS ABCS. Método brasileiro de classificação de carcaça. Estrela, RS, 1973. 17p. (Publicação Técnica n.2).

BANDEIRA, M.N. et al. Utilização d o milheto grão como substituto do milho em rações para suínos na fase de terminação. Arquivos das Escolas de Agronomia e Veterinária da Universidade Federal de Goiás, v.26, n.2, p.57-64, 1996.
BASTOS, A.O. et al. Composição química, digestibilidade dos nutrientes e da energia de diferentes milhetos (Pennisetum Glaucum (L.) R. Brown) em suínos. Revista Brasileira de Zootecnia, v.34, n.2, p.520-528, 2005.

BASTOS, A.O. et al. Diferentes níveis de grão de milheto (Pennisetum glaucum (L.) R. Brown) na alimentação de suínos. Revista Brasileira de Zootecnia, v.31, n.4, p1753-1760, 2002.

BELLAVER, C. et al. Radícula de malte na alimentação de suínos em crescimento e terminação. Pesquisa Agropecuária Brasileira, v.20, n.8, p.969-974, 1985.

BONAMIGO, L. A. A cultura do milheto no Brasil: implantação e desenvolvimento no cerrado. In: WORKSHOP INTERNACIONAL DE MILHETO, 1999, Planaltina, DF. Anais... Brasília: EmbrapaCPAC/Embrapa-CNPMS, 1999. p.31-68.

GERALDO, J. et al. Diferenças em crescimento e produção de grãos entre quatro cultivares de milheto pérola. Pesquisa Agropecuária Brasileira, v.35, n.7, p.1367-1376, 2000.

GOMES, M.F.M. et al. Análise econômica da utilização do triguilho para suínos. (S.L.): EMBRAPA - Centro Nacional de Pesquisa de Suínos e Aves, 1991. p.1-2 (Comunicado técnico, 179).

HULSE, J.H. et al. Sorghum and the millets: their composition and nutritive value. New York. Academic, 1980. $997 \mathrm{p}$.

JOHANSEN, H.N. et al. Effect of varying content of soluble dietary fiber from wheat flour and oat milling fraction on gastric emptying in pigs. British Journal of Nutrition, v.75, p.339$351,1996$.

KNUDSEN, K.E.B. Carbohydrate and lignin contents of plant materials used in animal feeding. Animal Feed Science and Technology, v.67, p.319-338, 1997. 
NICOLAIEWSKY, S.; PRATES, E.R. Alimentos e alimentação dos suínos. 3.ed. Porto Alegre: Universidade Federal do Rio Grande do Sul, 1987. 59p.

NIELSEN, E.K.; INGVARTSEN, K.L. Effect of cereal type, disintegration method and pelleting on stomach content, weight and ulcers and performance in growing pigs. Livestock Production Science, v.66, p.271-282, 2000.

NRC. Nutrients Requirements of Swine. 10.ed. Washington. DC: National Academic, 1998. 189p.

NUNES, R.C. et al. Utilização do milheto grão como substituto do milho em rações para suínos na fase de crescimento. Arquivos das Escolas de Agronomia e Veterinária da
Universidade Federal de Goiás, v.27, n.2, p.41-48, 1997.

RODRIGUES, P.B. et al. Aminoácidos digestíveis verdadeiros do milheto, do milho e subprodutos do milho, determinados com galos adultos cecectomizados. Revista Brasileira de Zootecnia, v.30, n.6S, p.2046-2058, 2001

UNIVERSIDADE FEDERAL DE VIÇOSA - UFV. SAEG Sistema de análises estatísticas e genéticas. Versão 7.1. Viçosa, MG, 1997. 150p. (Manual do usuário).

ZANOTTO, D.L. et al. Granulometria do milho em rações para engorda de suínos. S.L.: EMBRAPA, 1999. 2p. (Instrução Técnica para o Suinocultor, n.9). 